Article

\title{
Integration of SWOT-AHP Approach for Measuring the Critical Factors of Dairy Supply Chain
}

\author{
Rahul S. Mor ${ }^{1, * \mathbb{D}}$, Arvind Bhardwaj ${ }^{2}$ and Sarbjit Singh ${ }^{2}$ \\ 1 Department of Food Engineering, National Institute of Food Technology Entrepreneurship \& Management, \\ Kundli, Sonepat, Haryana 131028, India \\ 2 Department of Industrial \& Production Engineering, National Institute of Technology, Jalandhar 144011, \\ India; bhardwaja@nitj.ac.in (A.B.); balss@nitj.ac.in (S.S.) \\ * Correspondence: dr.rahulmor@gmail.com
}

Received: 28 January 2019; Accepted: 18 February 2019; Published: 24 February 2019

\begin{abstract}
Dairy farming is a subsidiary profession of agriculture in India where dairy cooperatives are an important part of rural development. The current study explores the critical factors in the dairy supply chain, and provides an initial decision framework for its implications. The necessary data were collected from dairy producer members including dairy farmers, executives, and key informants of processing units, to summarize the strengths, weaknesses, opportunities, threats (SWOT) of the milk processing system in India. This includes identifying the objectives of the dairy industry, along with the internal and external critical factors (CFs). SWOT exploration does not offer any investigative basis for evaluating the priorities of $\mathrm{CFs}$, therefore the analytic hierarchy process is applied to define the priorities of identified CFs. The CFs have also been ordered according to relative importance. The findings of this study depict that the SWOT based methodology offers vital sensitivity in assessing the supply chain strategies for the dairy industry.
\end{abstract}

Keywords: dairy industry; SWOT analysis; analytic hierarchy process (AHP), critical factors; multiple criteria decision making; supply chain

\section{Introduction}

India is a major milk producer globally, with 75.4 MT since 1998-99 by surpassing the USA, and 104 MT during 2007-2008 (Deptt. of animal husbandry and dairying, GoI). India has produced 4\% (approx.) of milk produced yearly, for three decades. Consequently, India has become a self-sufficient milk producing country globally. Sustainability in the agri-food sector is possible through innovations and R\&D, collaboration and green initiatives. Quality management is the significant factor in DSC subsequently the inventory management, supplier management and technological innovations [1-3]. The optimal effectiveness is required in the dairy sector to achieve better product quality and food safety $[4,5]$. Food producers, as well as processors, need to focus on the effective marketing strategies to target the rural market [6-8]. An analytic hierarchy process (AHP) approach allows the top management to measure the level of uniformity in finding the decision problems [9]. AHP is definitely an effective technique, since it gives the improved findings for tangible and intangible characteristics of a judgment. SWOT (strengths, weaknesses, opportunities, threats) is known as the best approach to analyze the factors scientifically and to formulate the strategies. Thus, SWOT analysis can be helpful for the identification of critical factors ( $\mathrm{CFs}$ ) in the dairy industry because the internal and external factors impact the processes in an enterprise. Deng et al. offered the revised TOPSIS with weighted Euclidean distances instead of demonstrating the weighted decision matrix [10]. Quantitative SWOT based method is feasible in assessing priorities of lean strategies [11]. 
The current paper attempts to explore the weaknesses and threats of the dairy industry together with the opportunities and strengths, and also the ranking of identified CFs to obtain priorities using AHP. Additionally, it merges the SWOT study for achieving the effectiveness of technological innovations in the milk processing sector [12-14]. However, the literature suggests that the assessment measures for alternatives can interrelate and not be autonomous in some cases. The best information the authors of this paper present is a foremost attempt of applying the AHP in the dairy sector. Section 1 includes the introduction part, and a comprehensive literature assessment is given in Section 2. Section 3 defines the scope of study along with the research methodology. Section 4 is the results and discussion part outlining the findings of the study. Finally, Section 5 derives the conclusions, and also recommending the directions for future research in this area.

\section{Literature Review}

Madaan et al. suggested focusing on CFs in food sector using AHP [15]. Dweiri et al. found that usage of AHP for supplier selection improves the consistency and robustness throughout the process [16]. Mor et al. addressed a review of the principles, bottlenecks, and strategies of supply chain practices of Indian agri-food sector and recommended to nurture the system effectiveness over policy direction $[17,18]$. Ayodele et al. recognized the challenges existing in unloading and knowledge optimization schemes into the food chain [19]. Studies proposes different ways of organizing the estates of DSC by means of indicators to measure them, exhibiting best operations and develop an ecological productive chain and analyzed the risk enablers in the dairy industry using an ISM tool and proposed a model for determining the performance of the integrated dairy supply chain [20]. The importance of various balanced scorecard (BSC) perspectives in India are different from developed countries because of the availability of setup, inconstant milk production, poor breed of cattle, deprived cold chain, etc. [21].

Ansari et al. recognized the key performance outcomes for the adoption of supply chain remanufacturing and prioritized the factors through hybrid fuzzy AHP and fuzzy TOPSIS approach [22]. De et al. worked on managing the demand at different ports during the planning horizon and the operational measures for reducing carbon emission, as well as performed the comparison analysis [23]. Ren et al. developed an improved multi-objective stochastic fuzzy programming method for agricultural water and land optimization [24]. Ray et al. demonstrated the steps of multiple criteria decision-making approaches for choosing the best alternative for in the context of site location selection [25]. De et al. addressed the issues of sustainability and safety in maritime transportation and proposed an integrated model, and also incorporated the issues of sustainability [26]. Dos et al. conducted a study to measure the criteria for sustainability models through AHP and identified fourteen application areas of AHP to support sustainable development [27]. SWOT methodology helps to solve complex strategic situations and improves the power of decision making [28]. Hisrich and Peters provided that the SWOT approach can be established to illuminate such real-life issues [29]. SWOT aids in defining key factors and scrutinize the threats through more consistent perusing [30]. AHP supports in exploring the complex problems and it translates them into a hierarchical structure [31-33]. Researchers assessed the market command of the origin supply chain for dairy sector through statistical measures and a nonlinear three-stage least square [34,35].

\section{Research Gaps}

The literature review reveals that there exists no study that evaluates the critical factors and their ranking in the dairy sector. SWOT procedures have been employed by researchers to identify the strength, weakness, opportunity and threat factors of diverse areas, but its applications in milk processing sector are limited. Furthermore, the application of AHP to rank the SWOT factors of the dairy industry has not been attempted yet. All the above causes drove the authors to plan the study presented in this paper. 


\section{Methodology}

A pre-tested schedule has been employed to accumulate the data from dairy producer members including dairy farmers, shop floor executives and key informants of milk processing units to summarize the factors and sub-factors related to strengths, weaknesses, opportunities, threats (SWOT) of the milk processing system in India. This includes identifying the objective of the dairy industry along with the internal and external critical factors (CFs) by developing pairwise comparisons among critical SWOT issues and assessing them through eigenvalue procedure. The methodology consists of three steps consists of identifying the $\mathrm{CFs}$ and sub-factors, prioritizing the $\mathrm{CFs}$, and calculating the inner dependency matrix and weights of factors. There exist many additional approaches like ELECTRE, TOPSIS, ISM, DEA, Extended PROMETHEE, etc. for the same situations. But, AHP is recommended as a superior means owing to its extensive applicability and simplicity of usage [36]. AHP is used to support multi-criteria decisions where the problem is divided into different components, i.e., analytical and hierarchy [9]. AHP method provides very satisfactory results and it has been used in various fields, such as process planning, selection of alternatives, optimization, and allocation of resources, etc. It combines both qualitative and quantitative aspects of ranking the alternatives [37,38]. So, the authors applied AHP to evaluate the CFs of DSC practices in the current study. The methodology flow chart is illustrated below (Figure 1).

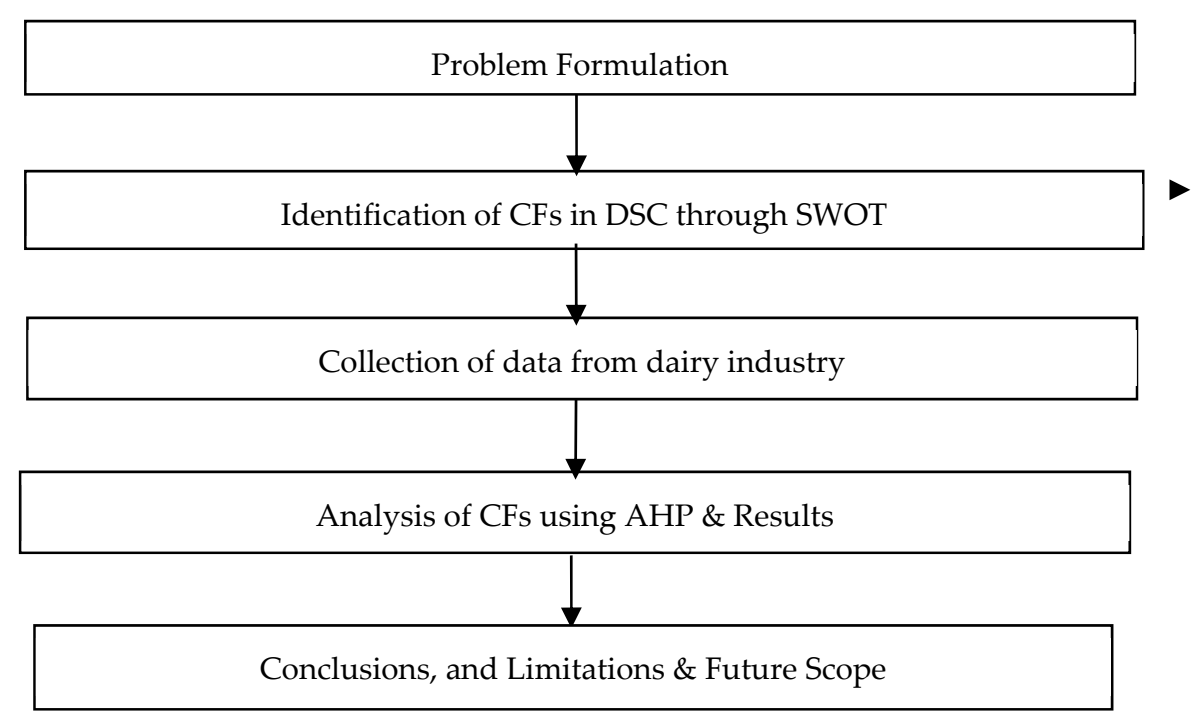

Figure 1. Methodology.

\section{AHP Approach}

Initially, a relation between the elements of the given problem is determined and then, the hierarchy model is built and finally, the consistency is checked whether the solution is feasible or not. The AHP steps are described below:

1. Preparation of the goal: Assessing the CFs to find their related priority.

2. Forming a pairwise assessment matrix: Pairwise assessment matrixes are formed from expert's feedback. The pairwise assessment matrix between the factors is accomplished by Saaty's scale (Table 1).

3. Determination of the Eigenvalues and Eigenvectors and comparative weights: The outlined pairwise comparison matrices are worked to establish the Eigenvalues and Eigenvectors and to compute the relative position of $\mathrm{CFs}$.

4. Assessment of the consistency ratio (CR): It is calculated to confirm the reliability of pairwise comparisons, as follows.

$$
\mathrm{CR}=\mathrm{CI} / \mathrm{RI},
$$


where consistency index $(\mathrm{CI})=\left(\lambda_{\max }-\mathrm{n}\right) /(\mathrm{n}-1),\left(\lambda_{\max }\right.$ is the max. average value $)$ and random consistency index (RI) relies upon value of (n). CR must be $\leq 0.10$ to have an improved level of consistency [20]. Table 2 presents the corresponding values of a random index [9].

Table 1. Scales in pairwise comparisons

\begin{tabular}{cc}
\hline Score & Definition \\
\hline 1 & Equal importance of both factors \\
\hline 3 & Limited importance of one factor over another \\
\hline 5 & Strong importance of one factor over another \\
\hline 7 & Very strong importance of one factor over another \\
\hline 9 & Extreme importance of one factor over another \\
\hline $2,4,6,8$ & Intermediate value between two close judgments \\
\hline
\end{tabular}

Table 2. Random Index (R.I.).

\begin{tabular}{rrrcccccc}
\hline $\mathbf{N}$ & $\mathbf{1}$ & $\mathbf{2}$ & $\mathbf{3}$ & $\mathbf{4}$ & $\mathbf{5}$ & $\mathbf{6}$ & $\mathbf{7}$ & $\mathbf{8}$ \\
\hline R.I. & 0 & 0 & 0.58 & 0.98 & 1.12 & 1.24 & 1.32 & 1.41 \\
\hline
\end{tabular}

\section{Analysis and Results}

A total of 28 issues, called as SWOT factors here, have been derived on the basis of comprehensive literature assessment and a pilot study, conducted in select dairy industries. These 28 factors comprised of seven strength factors, nine weakness factors, eight opportunity factors and four threat factors, as discussed below.

\subsection{Identification of CFs}

As discussed above, a total of $28 \mathrm{CFs}$ have been identified through SWOT analysis. Following are the identified CFs:

\section{A. Strength Factors}

S1. The purchasing power of the consumers is on the upswing with a growing economy and continually increasing population (PP).

S2. Milk consumption in northern India is a regular part of the dietary program irrespective of the region and hence demand is likely to rise continuously (MC).

S3. Labor cost is also fairly low which make the dairy industry a cost competitive (LC).

S4. Highly trained and qualified technical manpower is available at all levels to support R\&D, as well as industry operations (RD).

S5. Provides employment to the rural population, especially to women (WE). S6. A regular source of income for the farmers (FI).

S7. Use of two axis payment (based on Fat and SNF) system provides good milk producing price to the farmers (FP).

\section{B. Weakness Factors}

W1. Wastage of Water is an issue being faced by the dairy industry (WW).

W2. Poor roads connectivity to the villages makes milk procurement problematic (BR).

W3. Indian dairy market is divided into the unorganized and organized market out of which only $20 \%$ of the market is organized (OU).

W4. The two-axis payment system is good but static in nature, and the milk prices paid to the farmers are not revised regularly, due to which farmers get low milk prices as compared to the unorganized sector (PS).

W5. The distribution sector needs improvements and investments in the logistics and transportation phase (TF). W6. More refrigerated vehicles needed because of high perishable nature of milk products (AT).

W7. Operator's negligence is also a big issue in the milk processing plants. They need some strict rules and surveillance systems like CCTV and biometrics $(\mathrm{ON})$. 
W8. Lack of water treatment plant for processed water (WT).

W9. Use of plastic films which cause great danger to the environment, as well as to human health (PF).

\section{Opportunity Factors}

O1. Low milk output of animals makes a vast scope for improvement in milk production (AO).

O2. Potential of export, due to low production costs (EP).

O3. Use of dynamic payment system will lead to a better relationship between farmers and the organization, and it will also increase the farmer's profit (DPS).

O4. The packaging material may be replaced either with good quality cardboard, paper or glass bottles (PM).

O5. Making the farmers aware of the milk quality issues and chemical contaminants, as well as residual antibiotics (LA).

O6. The introduction of effective information systems will smoothen the flow of information throughout the dairy supply chain (IT).

O7. Use of automated milk collection units (AMC) will lead to:

O7.1. Savings in quantity of sample milk

O7.2. Savings of chemicals and detergents

O7.3. Savings of expenditure on glassware.

O7.4. Savings in stationery and time.

O7.5. Savings in expenditure on staff.

O7.6. Transparency at the collection level.

O8. Expansion of plant and investing in technological innovations and new technology will produce more jobs and self-employment opportunities (EP).

\section{Threat Factors}

T1. Low supplier satisfaction, as well as trust issues, if the dynamic payment system does not introduce into the milk procurement policy of the dairy industry (SS).

T2. People are not willing to pay more for high-quality products, due to high price sensitivity of dairy products (HP). T3. The market competition is increasing gradually, due to the presence of new players in the market (MC). T4. High investment needed in R\&D sector for new and featured products (RDI).

\subsection{Selection of CFs for $A H P$}

Out of the identified $28 \mathrm{CFs}$, only 17 factors are considered for AHP analysis in consultation with the professionals of the dairy industry, shop-floor executives, and academicians. The factors are selected based on their applicability and importance to the dairy industry. Following CFs have been carried forward for AHP analysis:

\section{A. Strengths}

S4. Highly trained and qualified technical manpower is available at all levels to support R\&D, as well as industry operations (RD).

S5. Provides employment to the rural population, especially to women (WE).

S6. A regular source of income for the farmers (FI).

S7. Use of two axis payment (based on Fat and SNF) system provides good milk producing price to the farmers (FP).

\section{B. Weaknesses}

W1. Wastage of Water is an issue being faced by the dairy industry (WW).

W3. Indian dairy market is divided into the unorganized and organized market out of which only $20 \%$ of the market is organized (OU).

W5. The distribution sector needs improvements and investments in the logistics and transportation phase (TF).

W8. Lack of water treatment plant for processed water (WT).

W9. Use of plastic films which cause great danger to the environment, as well as to human health (PF).

\section{Opportunities}

O2. Potential of export, due to low production costs (EP).

O3. Use of dynamic payment system will lead to a better relationship between farmers and the organization, and it will also increase the farmer's profit (DPS).

O6. The introduction of effective information systems will smoothen the flow of information throughout the dairy supply chain (IT).

O7. Use of automated milk collection units (AMC). 


\section{Threats}

T1. Low supplier satisfaction, as well as trust issues, if the dynamic payment system does not introduce into the milk procurement policy of the dairy industry (SS).

T2. People are not willing to pay more for high-quality products, due to high price sensitivity of dairy products (HP). T3. The market competition is increasing gradually, due to the presence of new players in the market (MC). T4. High investment needed in R\&D sector for new and featured products (RDI).

\subsection{Application of AHP}

The milk processing industries from northern India are selected to collect the data. The collected data is analyzed for ascertaining the priorities among different SWOT factors. Based on the literature review and the pilot study, all the 17 CFs are considered over here for AHP (as mentioned in Section 4). Given below is the hierarchy model for SWOT factors (Figure 2) the model represents various SWOT factors as criteria along with their sub-criteria.

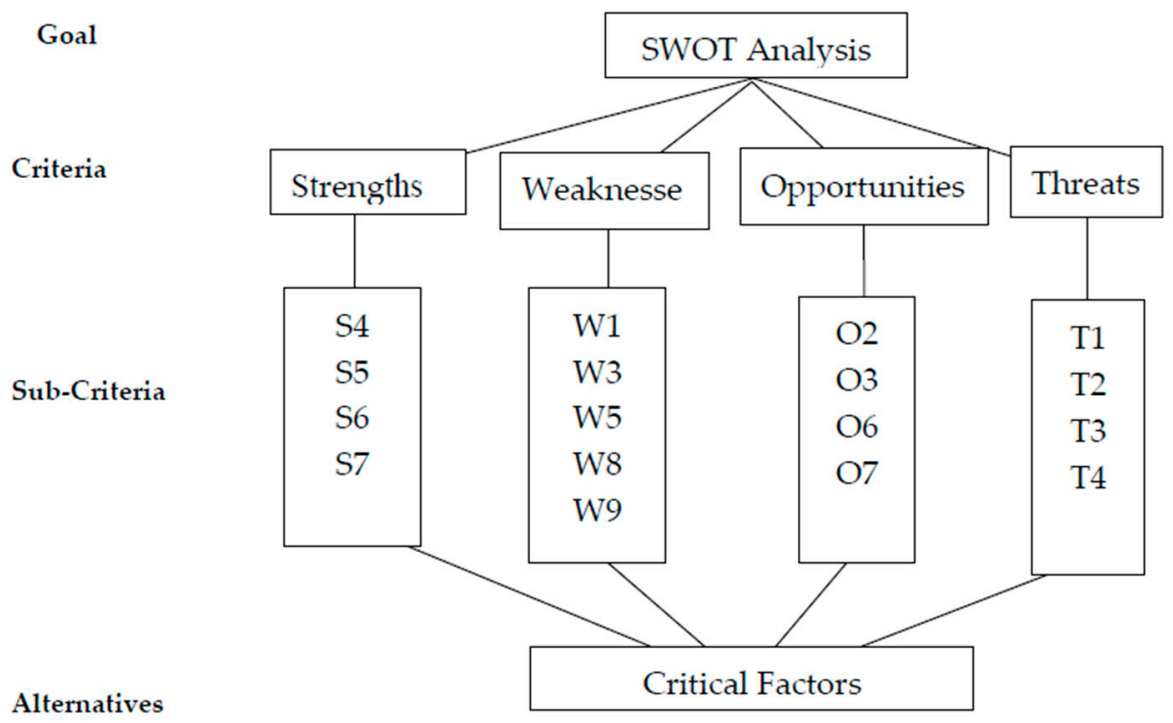

Figure 2. Hierarchy Model for SWOT Factors.

During the application of AHP to the case illustration, various pairwise assessment matrix is developed for the identified CFs, as follows.

Construction of the Pairwise Assessment Matrix

Various pairwise assessment matrix has been finalized in the below tables (Tables 3-7) for SWOT factor(s) analysis. The nine-point scale developed by Saaty (1980) has been adopted for assessing the interactions among CFs of DSCM practices for the study. Five experts from academics and five executives from dairy industry added their understanding to construct the SWOT factors. Then, the pairwise comparisons of SWOT groups using a Saaty's nine-point comparison scale were carried out in consultation with the experts' group. The SWOT factors are compared in view of every SWOT group. The experts shared their knowledge to build the comparison matrices and defined dependencies to achieve pairwise comparisons with added matrices. In this study, the percent agreement technique is used to reach a consensus in expert's judgments [39,40].

A. Strength Analysis

The strength factors have been analyzed for priority matrix, weight matrix and the calculations of strengths as follows. 
Table 3. Priority calculations for strength factors.

\begin{tabular}{|c|c|c|c|c|c|c|c|c|c|c|c|}
\hline \multicolumn{5}{|c|}{ Priority Matrix (a) } & \multicolumn{6}{|c|}{ Weight Matrix (W) } & \multirow{2}{*}{$\begin{array}{c}\text { Overall Priority } \\
a^{*} \mathbf{W}\end{array}$} \\
\hline & S4 & S5 & S6 & S7 & S4 & S5 & S6 & S7 & Weight (W) & Ranking & \\
\hline S4 & 1 & 1 & 0.5 & 2 & 0.23529412 & 0.39473684 & 0.10344828 & 0.22222222 & 0.23892536 & 3 & 0.95639909 \\
\hline S5 & 1 & 1 & 3 & 3 & 0.23529412 & 0.39473684 & 0.62068966 & 0.33333333 & 0.39601349 & 1 & 1.730122297 \\
\hline S6 & 2 & 0.2 & 1 & 3 & 0.47058824 & 0.07894737 & 0.20689655 & 0.33333333 & 0.27244137 & 2 & 1.107354127 \\
\hline S7 & 0.25 & 0.333333333 & 0.333333333 & 1 & 0.05882353 & 0.13157895 & 0.06896552 & 0.11111111 & 0.09261978 & 4 & 0.375169404 \\
\hline \multirow[t]{4}{*}{ Sum } & 4.25 & 2.533333333 & 4.833333333 & 9.000000001 & & & & & & & Sum $=4.169044918$ \\
\hline & & & & & & & & & & & $\mathrm{CI}=0.056348306$ \\
\hline & & & & & & & & & & & $\mathrm{RI}=0.98$ \\
\hline & & & & & & & & & & & $\mathrm{CR}=\mathrm{CI} / \mathrm{RI}=0.057498272$ \\
\hline
\end{tabular}

Table 4. Priority calculations for weakness factors.

\begin{tabular}{|c|c|c|c|c|c|c|c|c|c|c|c|c|c|}
\hline \multicolumn{6}{|c|}{ Priority Matrix (a) } & \multicolumn{7}{|c|}{ Weight Matrix (W) } & \multirow{2}{*}{$\begin{array}{c}\text { Overall Priority } \\
a^{*} \mathbf{W}\end{array}$} \\
\hline & W1 & W3 & W5 & W8 & W9 & W1 & W3 & W5 & W8 & W9 & Weight (W) & Ranking & \\
\hline W1 & 1 & 3 & 2 & 1 & 0.333333333 & 0.183486239 & 0.455696205 & 0.166666667 & 0.1199999996 & 0.133333333 & 0.211836488 & 2 & 1.218973494 \\
\hline W3 & 0.2 & 1 & 3 & 3.0000003 & 0.5 & 0.036697248 & 0.151898735 & 0.25 & 0.360000023 & 0.2 & 0.199719201 & 3 & 1.07529139 \\
\hline W5 & 0.25 & 0.25 & 1 & 0.333333333 & 0.333333333 & 0.04587156 & 0.037974684 & 0.083333333 & 0.0399999999 & 0.133333333 & 0.068102582 & 5 & 0.344438747 \\
\hline W8 & 1 & 0.3333333 & 3 & 1 & 0.3333333333 & 0.183486239 & 0.050632907 & 0.25 & 0.1199999996 & 0.133333333 & 0.147490495 & 4 & 0.754491533 \\
\hline W9 & 3 & 2 & 3 & 3 & 1 & 0.550458716 & 0.30379747 & 0.25 & 0.3599999987 & 0.4 & 0.372851235 & 1 & 2.05457833 \\
\hline \multirow[t]{4}{*}{ Sum } & 5.45 & 6.5833333 & 12 & 8.333333633 & 2.5 & & & & & & & & Sum $=5.447773494$ \\
\hline & & & & & & & & & & & & & $\mathrm{CI}=0.111943374$ \\
\hline & & & & & & & & & & & & & $\mathrm{RI}=1.12$ \\
\hline & & & & & & & & & & & & & $\mathrm{CR}=\mathrm{CI} / \mathrm{RI}=0.099949441$ \\
\hline
\end{tabular}


Based on the outcome of AHP for strength factors, all the CI, RI and CR scores are valid for AHP criteria (Table 3). The dairy industry is the major source of income to farmers and the participation of women at society level is considerable in rural areas. Thus, women empowerment is the first priority among the strengths (Table 3).

B. Weakness Analysis

The weakness factors have been analyzed for priority matrix, weight matrix and the calculations of weaknesses as follows.

Based on the outcome of AHP for weakness factors, all the CI, RI and CR scores are valid for AHP criteria (Table 4). Usage of plastic films for packaging the dairy products is the danger to the environment, as well as to human health, so it stands first as among the weaknesses and it needs to be focused first (Table 4).

C. Opportunity Analysis

The opportunity factors have been analyzed for priority matrix, weight matrix and the calculations of opportunities as follows.

Based on the outcome of AHP for opportunity factors, all the CI, RI and CR scores are valid for AHP criteria (Table 5). The introduction of effective information systems will smoothen the dairy supply chains. Thus, the execution of effective information technology is required in the dairy industry sector and it is the first priority among the opportunities (Table 5).

D. Threats Analysis

The threat factors have been analyzed for priority matrix, weight matrix and the calculations of threats as follows.

Based on the outcome of AHP for threat factors, all the CI, RI and CR scores are valid for AHP criteria (Table 6). Higher the supplier trust and satisfaction, higher will be the quality of raw material in case of any industry. Thus, supplier trust and satisfaction, timely and direct payment to farmers is must in the dairy industry and it is the first priority among threats (Table 6).

\subsection{Final SWOT Analysis}

After analyzing the priorities among each $\mathrm{CFs}$, a final ranking for the first ranked $\mathrm{CF}$ s in each pairwise matrix is calculated (Table 7). The first ranked CF in each matrix is further analyzed using AHP, as below: 
Table 5. Priority calculations for opportunity factors.

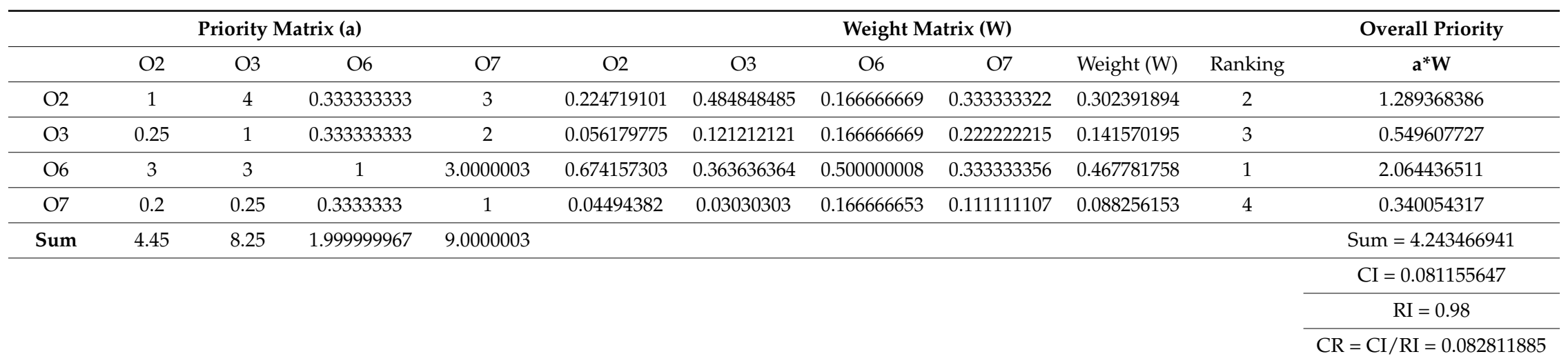

Table 6. Priority calculations for threat factors.

\begin{tabular}{|c|c|c|c|c|c|c|c|c|c|c|c|}
\hline \multicolumn{5}{|c|}{ Priority Matrix (a) } & \multicolumn{6}{|c|}{ Weight Matrix (W) } & \multirow{2}{*}{$\begin{array}{c}\text { Overall Priority } \\
a^{*} W\end{array}$} \\
\hline & $\mathrm{T} 1$ & $\mathrm{~T} 2$ & T3 & $\mathrm{T} 4$ & T1 & $\mathrm{T} 2$ & T3 & $\mathrm{T} 4$ & Weight (W) & Ranking & \\
\hline $\mathrm{T} 1$ & 1 & 3.0000003 & 3 & 3.0000003 & 0.521739149 & 0.333333356 & 0.4 & 0.642857166 & 0.474482417 & 1 & 2.051035281 \\
\hline $\mathrm{T} 2$ & 0.3333333 & 1 & 0.5 & 0.333333333 & 0.173913032 & 0.111111107 & 0.0666666667 & 0.071428567 & 0.105779843 & 4 & 0.427079001 \\
\hline T3 & 0.25 & 2 & 1 & 0.333333333 & 0.130434787 & 0.222222215 & 0.133333333 & 0.071428567 & 0.139354726 & 3 & 0.562996021 \\
\hline $\mathrm{T} 4$ & 0.3333333 & 3 & 3 & 1 & 0.173913032 & 0.333333322 & 0.4 & 0.214285701 & 0.280383014 & 2 & 1.17394751 \\
\hline \multirow[t]{4}{*}{ Sum } & 1.9166666 & 9.0000003 & 7.5 & 4.666666967 & & & & & & & Sum $=4.215057813$ \\
\hline & & & & & & & & & & & $\mathrm{CI}=0.071685938$ \\
\hline & & & & & & & & & & & $\mathrm{RI}=0.98$ \\
\hline & & & & & & & & & & & $\mathrm{CR}=\mathrm{CI} / \mathrm{RI}=0.073148916$ \\
\hline
\end{tabular}


Table 7. Priority calculations for Final SWOT factors.

\begin{tabular}{|c|c|c|c|c|c|c|c|c|c|c|c|}
\hline \multicolumn{5}{|c|}{ Final Priority Matrix (a) } & \multicolumn{6}{|c|}{ Weight Matrix (W) } & \multirow{2}{*}{$\begin{array}{c}\text { Overall Priority } \\
a^{*} W\end{array}$} \\
\hline & S5 & W9 & O6 & $\mathrm{T} 1$ & S5 & W9 & O6 & T1 & Weight (W) & Ranking & \\
\hline S5 & 1 & 0.333333333 & 0.333333333 & 0.5 & 0.111111111 & 0.153846154 & 0.090909091 & 0.076923077 & 0.108197358 & 4 & 0.434537684 \\
\hline W9 & 3 & 1 & 2 & 2 & 0.333333333 & 0.461538462 & 0.545454546 & 0.307692306 & 0.412004662 & 1 & 1.696192696 \\
\hline O6 & 3 & 0.33333333 & 1 & 3.00000003 & 0.333333333 & 0.153846153 & 0.272727273 & 0.461538464 & 0.305361306 & 2 & 1.290598294 \\
\hline $\mathrm{T} 1$ & 2 & 0.5 & 0.33333333 & 1 & 0.222222222 & 0.230769231 & 0.09090909 & 0.153846153 & 0.174436674 & 3 & 0.698620822 \\
\hline \multirow[t]{4}{*}{ Sum } & 9 & 2.166666663 & 3.666666663 & 6.50000003 & & & & & & & Sum $=4.119949497$ \\
\hline & & & & & & & & & & & $\mathrm{CI}=0.039983166$ \\
\hline & & & & & & & & & & & $\mathrm{RI}=0.98$ \\
\hline & & & & & & & & & & & $\mathrm{CR}=\mathrm{CI} / \mathrm{RI}=0.040799149$ \\
\hline
\end{tabular}


Based on the outcome of AHP for all the four factors, i.e., the first ranked strength, weakness, opportunity and threat factors prioritized above (Tables 3-6), all the calculated CI, RI, and CR scores are valid for final AHP criteria (Table 7). The final results of the ranking (Table 7) are as follows:

- $\quad$ 1st Rank: Usage of plastic films for packaging dairy products.

- 2nd Rank: Execution of effective information technology systems.

- 3rd Rank: Supplier trust and satisfaction, as well as timely and direct payment to farmers.

- 4th Rank: Womens' empowerment.

\subsection{Determining the Preference Weight}

The weights have been calculated for giving preference to the critical factors and each factor is recognized according to their respective weight (as given in above tables). On the basis of the preference weights, the factors are listed according to their priorities that could be useful in the adoption of efficient DSCM practices resulting in updating the dairy industry database which in turn is helpful in improving the dairy supply chain support system.

\subsection{Analysis of Results and its Implication}

The consistency ratio of the given criteria is $\mathrm{CI} \geq 0.1$. The priority order of the factors is given as $\mathrm{PF}>\mathrm{IT}>\mathrm{SS}>\mathrm{WE}$. It is as further described in details as:

- The use of plastic films (PF) ranks first on the priority list and it has the highest priority in comparison to the other critical factors in this study. This factor is critical to the environment point of view also.

- The execution of effective information technology systems (IT) ranks second on the priority list and it plays an important role in smoothening the dairy supply chains.

- The supplier satisfaction and trust (SS) holds the third place in the priority list which is a must variable in any supply chain system, irrespective of the industry or sector.

- Women Empowerment (WE) acquires the fourth important level. This factor is basically the industry-specific and it is the major source of employment and involvement of women in the dairy industry. This also implies to the rural empowerment of India population.

\section{Conclusions}

The current study is aimed to propose a framework for the identification and assessment of the $\mathrm{CFs}$ in the dairy supply chain, using the AHP approach. The data collection and findings in this study are based on expert views and data collected from various dairy units. After a comprehensive literature survey and pilot study, a total of $28 \mathrm{CFs}$ were identified and analyzed for their importance in the context of the dairy industry. Total $17 \mathrm{CFs}$ (four strengths, five weaknesses, four opportunities and four threats) are carried forward for further ranking. First, the authors calculated the priorities of $17 \mathrm{CFs}$ in their respective groups (Tables 3-6) and prioritized the overall outcome of SWOT analysis (Table 7) also in the second step. Out of these 17 factors, authors further choose the 4 crucial factors that have the highest influence in their respective SWOT group. The proposed SWOT-AHP approach Thus, the contribution of this study is empirical, as well as practical for the dairy industry. The empirical analysis reveals that that $\mathrm{PF}$ is extremely prioritized over other $\mathrm{CFs}$, whereas the relative importance of $\mathrm{CFs}$ comes out to be: PF $>$ IT $>$ SS $>$ WE. The practical aspects of this research depict that the future dairy necessitates the involvement of small dairy farmer and emphasis on the CFs along with technological innovations and sustainable supply chain strategies. The dairy industry has high potential in rural development and women empowerment and hence, needs more investment in this sector. There is a need to improve the quality of services, and reduce in the cost of services delivered, so farmers can profit more. 


\section{Limitations and Future Scope}

The SWOT study along with the AHP can be applied to various other case studies of agri-food sector, such as meat, poultry, fishery, bakery, etc. In order to generalize the application of this procedure, it may be tested to evaluate the supply chain practices in private dairy units also. Furthermore, the application of the approaches like DEA, goal programming, metaheuristics, ISM, Extended PROMETHEE, QFD, etc. could also be tested for validation of the results obtained in the current study.

Author Contributions: The authors designed the study jointly. R.S.M. carried out the conceptualization, data collection and analysis part. A.B. and S.S. contributed mainly to theory building as well as research plan of the study. All authors read and approved the final manuscript.

Funding: This research received no external funding.

Conflicts of Interest: The authors declare no conflict of interest.

\section{References}

1. Mor, R.S.; Bhardwaj, A.; Singh, S. Benchmarking the interactions among performance indicators in Dairy supply chain: An ISM approach. Benchmark. Int. J. 2018, 25, 3858-3881. [CrossRef]

2. Mor, R.S.; Bhardwaj, A.; Singh, S. A structured-literature-review of the supply chain practices in Dairy industry. J. Oper. Supply Chain Manag. 2018, 11, 14-25. [CrossRef]

3. Mor, R.S.; Bhardwaj, A.; Singh, S. Benchmarking the interactions among barriers in Dairy supply chain: An ISM approach. Int. J. Q. Res. 2018, 12, 385-404.

4. Bhardwaj, A.; Mor, R.S.; Singh, S.; Dev, M. An investigation into the dynamics of supply chain practices in Dairy industry: A pilot study. In Proceedings of the 2016 International Conference on Industrial Engineering \& Operations Management, Detroit, MI, USA, 23-25 September 2016; pp. 1360-1365.

5. Mor, R.S.; Bhardwaj, A.; Singh, S.; Kharub, M. Framework for measuring the performance of procurement practices in dairy industry. In Sustainable Procurement in Supply Chain Operations; CRC Press-Taylor \& Francis Group: Boca Raton, FL, USA, 2018.

6. Mor, R.S.; Bhardwaj, A.; Singh, S. A structured literature review of the Supply Chain practices in Food Processing Industry. In Proceedings of the 2018 International Conference on Industrial Engineering \& Operations Management, Bandung, Indonesia, 6-8 March 2018; pp. 588-599.

7. Mor, R.S.; Singh, S.; Bhardwaj, A.; Bharti, S. Exploring the causes of low-productivity in Dairy industry using AHP. J. Teknik Ind. 2017, 19, 83-92. [CrossRef]

8. Mor, R.S.; Singh, S.; Bhardwaj, A. Learning on lean production: A review of opinion \& research within environmental constraints. Oper. Supply Chain Manag. Int. J. 2016, 9, 61-72.

9. Saaty, T.L. The Analytic Hierarchy Process: Planning, Priority Setting, Resource Allocation; McGraw: New York, NY, USA, 1980.

10. Deng, H.; Yeh, C.H.; Willis, R.J. Inter-company comparison using modified TOPSIS with objective weights. Comput. Oper. Res. 2000, 27, 963-973. [CrossRef]

11. Prasad, S.; Khanduja, D.; Sharma, S.K. Integration of SWOT analysis with hybrid modified TOPSIS for the lean strategy evaluation. Proc. IMechE Part B J. Eng. Manuf. 2016, 1-15. [CrossRef]

12. Sevkli, M.; Oztekin, A.; Uysal, O. Development of a fuzzy ANP based SWOT analysis for the airline industry in Turkey. Expert Syst. Appl. 2012, 39, 14-24. [CrossRef]

13. Shinno, H.; Yoshioka, H.; Marpaung, S. Quantitative SWOT analysis on global competitiveness of machine tool industry. J. Eng. Des. 2006, 17, 251-258. [CrossRef]

14. Yuksel, I.; Dagdeviren, M. Using the analytic network process (ANP) in a SWOT analysis: A case study for a textile firm. Inform. Sci. 2007, 177, 3364-3382. [CrossRef]

15. Madaan, J.; Mangla, S. Decision modeling approach for eco-driven flexible green supply chain. Syst. Flex. Bus. Agility 2015, 343-364. [CrossRef]

16. Dweiri, F.; Kumar, S.; Khan, S.A.; Jain, V. Designing an integrated AHP based decision support system for supplier selection in automotive industry. Expert Syst. Appl. 2016, 62, 273-283. [CrossRef]

17. Mor, R.S.; Jaiswal, S.K.; Singh, S.; Bhardwaj, A. Demand Forecasting of Short-Lifecycle Dairy Products. In Understanding the Role of Business Analytics; Springer Nature Singapore: Singapore, 2018. [CrossRef] 
18. Mor, R.S.; Singh, S.; Bhardwaj, A.; Singh, L.P. Technological implications of supply chain practices in agri-food sector-A review. Int. J. Supply Oper. Manag. 2015, 2, 720-747.

19. Ayodele, A.B.; Ellis, L.; Turner, P. Identifying key research challenges in investigating knowledge optimization strategies in perishable food chains. In Proceedings of the 11th International Conference on Intellectual Capital, Knowledge Management \& Organizational Learning, University of Sydney, Sydney, Australia, 6-7 November 2014.

20. Kumar, A.; Staal, S.J.; Singh, D.K. Smallholder dairy farmers' access to modern milk marketing chains in India. Agric. Econ. Res. Rev. 2011, 24, 243-253.

21. Prakash, G.; Pant, R.R. Performance measurement of a dairy supply chain: A balance scorecard perspective. In Proceedings of the 2013 IEEE-IEEM, Bangkok, Thailand, 10-13 December 2013; pp. 196-200.

22. Ansari, Z.N.; Kant, R.; Shankar, R. Prioritizing the performance outcomes due to adoption of critical success factors of supply chain remanufacturing. J. Clean. Prod. 2019, 212, 779-799. [CrossRef]

23. De, A.; Kumar, S.K.; Gunasekaran, A.; Tiwari, M.K. Sustainable maritime inventory routing problem with time window constraints. Eng. Appl. Artif. Intell. 2017, 61, 77-95. [CrossRef]

24. De, A.; Mamanduru, V.K.R.; Gunasekaran, A.; Subramanian, N.; Tiwari, M.K. Composite particle algorithm for sustainable integrated dynamic ship routing and scheduling optimization. Comput. Ind. Eng. 2016, 96, 201-215. [CrossRef]

25. Ren, C.; Li, Z.; Zhang, H. Integrated multi-objective stochastic fuzzy programming and AHP method for agricultural water and land optimization allocation under multiple uncertainties. J. Clean. Prod. 2019, 210, 12-24. [CrossRef]

26. Ray, A.; De, A.; Dan, P.K. Facility location selection using complete and partial ranking MCDM methods. Int. J. Ind. Syst. Eng. 2015, 19, 262-276. [CrossRef]

27. De, A.; Choudhary, A.; Tiwari, M.K. Multiobjective approach for sustainable ship routing and scheduling with draft restrictions. IEEE Trans. Eng. Manag. 2019, 66, 35-51. [CrossRef]

28. De, A.; Awasthi, A.; Tiwari, M.K. Robust formulation for optimizing sustainable ship routing and scheduling problem. IFAC-PapersOnLine 2015, 48, 368-373. [CrossRef]

29. Dos Santos, P.H.; Neves, S.M.; Sant'Anna, D.O.; de Oliveira, C.H.; Carvalho, H.D. The analytic hierarchy process supporting decision making for sustainable development: An overview of applications. J. Clean. Prod. 2019, 212, 119-138. [CrossRef]

30. Learned, E.P.; Christensen, C.R.; Andrews, K.R. Business Policy: Text E Cases; McGraw-Hill/Irwin: Homewood, IL, USA, 1969.

31. Hisrich, R.D.; Peters, M.P. Entrepreneurship: Starting, Developing, E Managing a New Enterprise; McGraw-Hill/Irwin: Boston, MA, USA, 1992.

32. Kotler, P. Marketing Management; Prentice-Hall: Upper Saddle River, NJ, USA, 2000.

33. Luthra, S.; Mangla, S.K.; Xu, L.; Diabat, A. Using AHP to evaluate barriers in adopting sustainable consumption \& production initiatives in a supply chain. Int. J. Prod. Econ. 2016, 181, 342-349.

34. Govindan, K.; Kaliyan, M.; Kannan, D.; Haq, A.N. Barriers analysis for green supply chain management implementation in Indian industries using analytic hierarchy process. Int. J. Prod. Econ. 2014, 147, 555-568. [CrossRef]

35. Lemma, H.R.; Singh, R.; Kaur, N. Determinants of supply chain coordination of milk and dairy industries in Ethiopia: A case of Addis Ababa and its surroundings. SpringerPlus 2015, 4, 498. [CrossRef] [PubMed]

36. Ho, W. Integrated analytic hierarchy process \& its applications-A literature review. Eur. J. Oper. Res. 2008, $186,211-228$.

37. Yang, Y. SWOT-TOPSIS integration method for strategic decision. In Proceedings of the International Conference on E-Business \& E-Government, Guangzhou, China, 7-9 May 2010; pp. 1575-1578.

38. Harputlugil, T.; Prins, M.; Tanju, G.A.; Ilker, T.Y. Conceptual framework for potential implementations of multi criteria decision making (MCDM) methods for design quality assessment. In Proceedings of the CIB International Conference, Delft University of Technology, Amsterdam, The Netherlands, 20-23 June 2011. 
39. Saaty, T.L. Fundamentals of Decision Making \& Priority Theory with the Analytic Hierarchy Process; RWS Publications: Pittsburgh, PA, USA, 2000; Volume 6.

40. Vaidya, O.S.; Kumar, S. Analytic hierarchy process: An overview of applications. Eur. J. Oper. Res. 2006, 169, 1-29. [CrossRef]



(C) 2019 by the authors. Licensee MDPI, Basel, Switzerland. This article is an open access article distributed under the terms and conditions of the Creative Commons Attribution (CC BY) license (http:/ / creativecommons.org/licenses/by/4.0/). 